\section{Esophageal Stent in the Anus: An Unusual Presentation of Stent Migration}

Implantation of prostheses is the principal option for palliative treatment of malignant dysphagia, but peri-interventional complications remain a concern. We report here on the case of a 71-year-old male patient with inoperable esophageal cancer who was admitted to our department with postprandial regurgitation, dysphagia, and inability to pass stool. He denied experiencing any pain or symptoms of bleeding. One month previously, a conventional esophageal plastic stent (11/60 esophageal tube, ESKA-Buess, Germany) had been implanted at an outside department to bridge a high-grade malignant stenosis located approximately $20 \mathrm{~cm}$ above the gastroesophageal junction; the tube did not bridge the cardia (Figure 1). Physical examination revealed

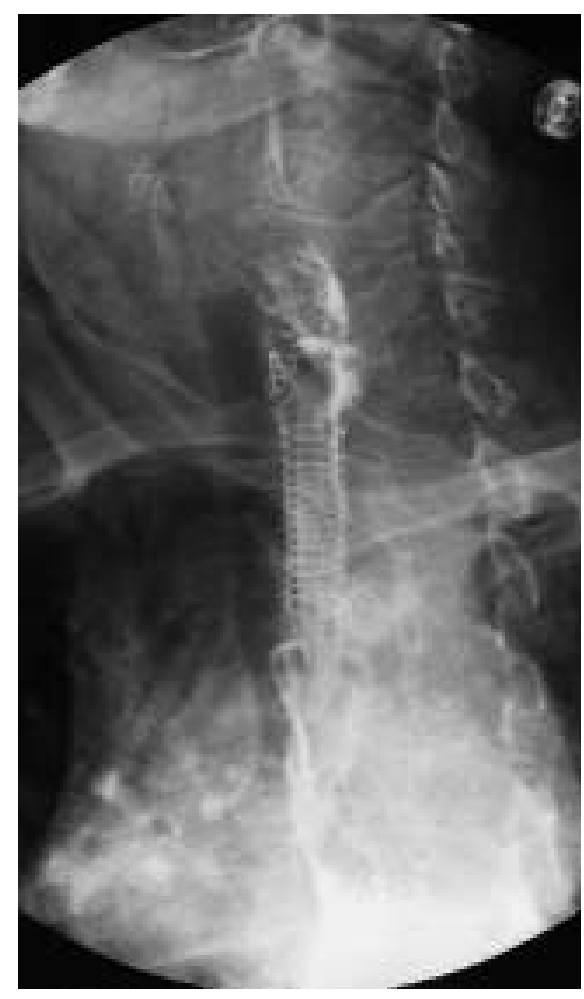

Figure 1 Chest radiograph with water-soluble contrast meal after placement of the esophageal plastic stent (ESKA-Buess 11/60 esophageal tube), showing the stent in the correct position. a stool-filled stent, visible in the anus. The esophageal plastic stent had passed through the entire gastrointestinal tract without causing any obvious migrationrelated symptoms or complications. It was easily removed from the anus manually.

Gastroscopy with bougienage of the esophageal stenosis and implantation of a coated self-expanding metal stent (SEMS) were carried out, substantially improving the patient's dysphagia. Later, dysphagia recurred due to tumor overgrowth at both ends of the stent, requiring thermocoagulation followed by extension of the stent using a second SEMS. Palliative radiotherapy for tracheal tumor infiltration and implantation of a percutaneous endoscopic gastrostomy (PEG) feeding tube under fluoroscopic guidance were necessary.

Distally migrated esophageal stents may remain in the stomach without problems, cause obstruction in the gastrointestinal tract, or pass unrecognized per rectum [1]. Migration occurs significantly more frequently with plastic stents than with SEMS prostheses [2]. Metal stents may become enmeshed in the tumor making migration unlikely. However, stent fracture and consequent migration [3] and rectal bleeding caused by a migrated stent [4] have been reported with SEMS. This is the first report of a displaced esophageal plastic stent with asymptomatic migration through the entire gastrointestinal tract, finally presenting in the anus filled with stool and causing stool retention.

\section{Kazemi-Shirazi ${ }^{1}$, A. Püspök ${ }^{1}$, R. Schöfl ${ }^{1}$, A. Ferlitsch ${ }^{1}$, M. R. Müller ${ }^{2}$, A. Gangl ${ }^{1}$, G. Novacek ${ }^{1}$ \\ ${ }^{1}$ Dept. of Internal Medicine IV, Division of Gastroenterology and Hepatology, Vienna, Austria \\ 2 Dept. of Cardio-Thoracic Surgery, University of Vienna, Vienna, Austria}

\section{References}

${ }^{1}$ Siersema PD, Hop WC, Dees J et al. Coated self-expanding metal stents versus latex prostheses for esophagogastric cancer, with special reference to prior radiation and chemotherapy: a controlled, prospective study. Gastrointest Endosc 1998; 47: 113 - 120

${ }^{2}$ Knyrim K, Wagner HJ, Bethge N et al. A controlled trial of an expansile metal stent for palliation of esophageal obstruction due to inoperable cancer. N Engl J Med 1993; 329: 1302 - 1307

${ }^{3}$ Grimley CE, Bowling TE. Oesophageal metallic stent dysfunction: first reported case of stent fracture and separation. Endoscopy 1999; 31: S45

${ }^{4}$ Begbie S, Briggs G, Levi J. A late complication of palliative stenting of malignant esophageal obstruction. Aust N Z Med 1996; 26: 115

\section{Corresponding Author}

\section{Kazemi-Shirazi, M.D.}

Department of Internal Medicine IV

Division of Gastroenterology

and Hepatology

University of Vienna

Währinger Gürtel 18-20

1090 Vienna

Austria

Fax: + 43-1-40400-4735

E-mail: Lili.Kazemi-Shirazi@ akh-wien.ac.at 